\title{
O SAGRADO E O PROFANO NO RETÁBULO DE SANTA JOANA CAROLINA DE OSMAN LINS
}

\author{
Júlio César de Carvalho Santos
}

RESUMO: O presente artigo tem como corpus analisar o conto Retábulo de Santa Joana Carolina. Focaliza-se o estudo das marcas inferenciais presentes nessa narrativa que viabilizam as concepções religiosas e profanas contidas em seu enredo. Este trabalho tem por objetivo investigar as simbologias religiosas presentes na obra e os comportamentos característicos dos signos do zodíaco. Para isso, baseamo-nos nos conceitos de inferência de leitura e nas concepções dialógicas de Bakhtin. A análise foi feita a partir da retirada de alguns trechos do conto que demonstram indícios vinculados ao ambiente religioso e astrológico e comparamos com versículos bíblicos e com a análise comportamental dos signos. Como resultado, notamos que Osman Lins, no decorrer da narrativa, propõe indícios que, comparados a passagens bíblicas e estudos dos signos, são referenciais para uma leitura interpretativa que transcende o contexto, despertando o conhecimento prévio do leitor. Assim, conclui-se que o leitor, ao relacionar seus conhecimentos, torna-se capaz de compor novas perspectivas de leitura, através de relações dialógicas e inferenciais permitidas pelo texto.

Palavras-chave: Dialogismo; Inferência; Concepções de Leitura; Osman Lins

\section{INTRODUÇÃO}

A criatividade e a essência da palavra ilustram a obra de Osman Lins, um autor cujo trabalho caracteriza-se pela forma variada de inserir, no contexto de suas histórias, manifestações de criatividade que uma mera leitura não abarcará, por inteiro, o que de fato suas inventivas linhas contam e escondem. Esse olhar místico e inovador é, de fato, o que mais agrada leitores apaixonados por enredos desprendidos do habitual e vinculados a um caminho de descobertas e provocações, através de uma leitura repleta de enigmas e valores.

Das diversas produções do autor, uma em especial, será o objeto de análise do presente artigo, o conto Retábulo de Santa Joana Carolina, que se 
encontra no livro Nove, Novena, de 1966. Destacando marcas inferenciais que viabilizam as concepções religiosas e profanas contidas em seu enredo.

O conto Retábulo de Santa Joana Carolina remete-nos, inicialmente, a uma história circundada pelo viés religioso. Todavia, o leitor mais atento percebe que o escritor já inicia o texto com inserções astrológicas das quais se distanciam dos princípios sagrados tradicionais. Por tal motivo, este trabalho tem por objetivo investigar as simbologias religiosas contidas na obra e os comportamentos característicos dos signos do zodíaco. Para que isso fosse feito, foram apresentados alguns pontos significativos da estrutura narrativa e expostos elementos semelhantes às passagens bíblicas. Além disso, contextualizaram-se as relevâncias de leitura a partir das inferências que o leitor poderá atribuir ao texto.

Em se tratando de um conto em que o conhecimento prévio de leitura poderá ser a chave para distinguir os propósitos contextuais da narrativa, esta pesquisa se justifica à intenção de mostrar como a tessitura do texto em questão demanda um leitor ativo no processo de leitura o qual, a partir de suas inferências e contextos sociais, é capaz de atribuir ao texto referências que lhe podem soar como familiar e instigante. Dessa maneira, o conto desnuda-se como um feixe de significados, já que permite ao leitor atribuir sentidos ao contexto a partir das relações que este faz da narrativa com o discurso religioso, o discurso astrológico e a estrutura tradicional da narrativa.

Empreenderemos nosso trabalho baseando-nos, principalmente, nas contribuições de Bakhtin, a partir do conceito de Dialogismo abordados por Fiorin (2016) e Cereja (2005). Apresentaremos os estudos realizados da biografia de Osman Lins e da estrutura de sua narrativa, juntamente com a análise de Cândido (1987) referente à personagem de ficção. Quanto aos procedimentos de leitura, retrataremos a proposta de Coscarelli (2002 e 2003) sobre as reflexões que faz da relevância das inferências no ato de ler.

Para conduzir este estudo, foram retiradas do texto algumas partes, que analisadas, expõem as evidências dos valores religiosos, das simbologias da astrologia e das diferenças entre a estrutura do conto em análise e a estrutura tradicional da narrativa. A partir dessa seleção foram analisados os objetivos pretendidos com este estudo.

\section{PRESSUPOSTOS TEÓRICOS}

\section{INFERÊNCIAS DE LEITURA}

O processo de leitura exige uma interação entre o texto e o leitor. Essa interação é necessária para que o leitor possa compreender o propósito do texto e atribuir a ele significados. A partir desse processo interativo, o leitor poderá adquirir conhecimento e acrescentá-lo ao conhecimento que já possui. Assim, justifica-se o que Coscarelli (2002) afirma quando menciona que, para a compreensão textual, é necessário haver uma combinação entre a informação exposta no texto e o conhecimento do leitor. 
Em outras palavras, o texto leva o leitor a articular o seu conhecimento prévio para preencher determinadas "lacunas" em seu contexto. Esse procedimento, que, muitas vezes, é conhecido como os meios implícitos textuais, é direcionado ao conceito de inferência. Contudo, conforme Vargas (2015), o processo de inferenciação não pode se vincular apenas ao preenchimento dessas "lacunas", pois, dessa maneira, a inferência estaria voltada a um procedimento de leitura ascendente bottom - up (processo de decodificação, em que o leitor tem o texto como parâmetro, sem fazer inferências sobre ele) não permitindo nenhuma interatividade.

O conceito de inferência, conforme Coscarelli (2002), está atrelado ao processo de compreensão, e esse vínculo, ainda não permite uma contextualização adequada, pois cada leitor poderá realizar uma inferência, de acordo com o conhecimento e expectativas que o conteúdo irá lhe trazer. Embora haja uma relativa liberdade para as inferências feitas pelo leitor, Coscarelli (2003) defende que as inferências feitas pelo receptor do texto devem ser permitidas pelo contexto, caso contrário, poderão surgir leituras contraditórias do que foi proposto pelo autor.

As inferências, de certo modo, aparecem no processo de leitura, pois, conforme Vargas (2015), a inferência é uma operação necessária no texto, pois o autor nem sempre consegue expressar tudo o que pretende de forma explícita. O texto, portanto, conforme Coscarelli (2002) não precisa ser muito explícito porque os leitores são capazes de preenchê-lo, com inferências, as informações.

Outro aspecto sobre o conceito de inferência são os critérios apresentados por Coscarelli (2003) sobre o que seria de fato uma inferência. O primeiro viabiliza o procedimento de inferenciação quando o leitor acrescenta informações que não foram inseridas na composição textual; o segundo, quando o leitor tem a opção de inserir uma informação, se a informação for obrigatória perderá o valor inferencial.

Em suma, a inferência é um procedimento, por meio do qual,o leitor interage com o texto, depositando nele seu conhecimento de mundo para atribuir um significado às informações não explicitadas. A partir do significado atribuído pelo leitor, ele será capaz de estabelecer compreensão e conseguirá interagir com a proposta pretendida pelo autor, contudo, conforme exposto, essas inferências não podem extrapolar o contexto exposto no texto para não ocorrer leituras contraditórias.

\section{DIALOGISMO NA PERSPECTIVA BAKHTINIANA.}

O dialogismo denota uma relação entre o eu e o outro na construção e compreensão do enunciado. Esse processo interdiscursivo propõe relações sociais que influenciam na composição do enunciado, assim como afirma Brait (2011, p. 94-95): 
[..] o enunciado diz respeito ao permanente diálogo, nem sempre simétrico e harmonioso, existente entre os diversos discursos que configuram uma comunidade, uma cultura, uma sociedade. É nesse sentido que podemos interpretar o dialogismo como elemento que instaura a constitutiva natureza interdiscursiva da linguagem.

Essa relação interdiscursiva, como citado por Brait (2011), interfere na receptividade do enunciado. O receptor fará jus ao propósito indiciado pelo texto a partir de seu conhecimento prévio e das instâncias que julgar mais apropriadas ao seu conhecimento. Este, portanto, torna-se o desafio de uma produção textual ou visual: estabelecer uma relação dialógica com o leitor ou espectador, com a finalidade de promover interação e despertar o interesse pela obra.

As interrelações dialógicas desempenham um papel fundamental na construção do enunciado. Para as concepções bakhtinianas, de certo modo, todas as obras são referenciadas por conceitos já apresentados de alguma maneira, ou seja, não há conceitos isolados, e sim, uma interação com outros autores e teorias cuja inserção, em um determinado contexto, poderá acontecer de maneira involuntária.

Conforme os estudos realizados por Bakhtin, pode-se afirmar que a língua é permeada por inúmeras influências do meio, consequentemente, o modo como o indivíduo produz o discurso revela seu perfil e sua relação com a linguagem. O autor, portanto, sugere uma filosofia da linguagem, cujos valores permitem observar por que ela é permeada de ideologias e comportamentos que envolvem as questões do sujeito no mundo e sua interação no meio social.

\section{CONSIDERAÇÕES SOBRE O AUTOR E A OBRA}

Osman da Costa Lins nasceu em Vitória de Santo Antão em Pernambuco, em 05 de julho de $1924^{1}$. Com um jeito singular de escrever, foi considerado um grande nome da nossa literatura devido à sua habilidade de transgredir formas tradicionais de escrita, assim como Guimarães Rosa. O que o caracteriza também foi a sua identificação com o contexto nacional brasileiro, apesar de ter sido traduzido em várias línguas, manteve-se fiel à sua cultura. Assim como menciona Andrade (1987, p. 18):

[...] sua obra atesta a experiência de uma vida que se desloca do nordeste ao sul do país, sintetizando e rompendo tendências literárias que não só refletem as suas raízes como também ampliam-nas a um contexto artístico e cultural mais vasto e contemporâneo.

Provindo de uma geração modernista em que a prosa fora intitulada como intimista, Lins se desvincula de contextos antigos e atrai os leitores a

\footnotetext{
${ }^{1}$ Fonte:< http://www.osmanlins.nom.br/pg_vida.htm> Acesso em 09 de fev. 2017.
} 
uma nova linguagem que exige um caminhar de leitura mais voltado à introspectividade. Assim como os admiradores de Clarice Lispector, aqueles que apreciam seu jeito de escrever são envolvidos por uma natureza psicológica cujo cenário se dispõe tanto de valor contextual quanto estrutural da narrativa. Bosi (2012, p. 422) relata-nos como essa criatividade introspectiva e estrutural se revela na obra enigmática do autor:

\begin{abstract}
O escritor pernambucano mostrou-se sensível à notação psicológica no romance $O$ Visitante (1955) e nos contos maduros e exemplares de Os Gatos (1957); ascendeu à fusão de clima regional (sem pitoresco...) e à sondagem interior na prosa densa de O Fiel e a Pedra, romance (1961); e experimentou, nas "narrativas" de Nove, Novena (1966) as virtualidades de uma ficção complexa, não raro hermética, mas realmente nova: pela consciência construtiva, pelo uso de símbolos gráficos que abrem e pontuam o monólogo interior; enfim, pela tensão metafísica que supera o nível psicológico "médio" e meridiano e desvenda nexos mais íntimos e dinâmicos entre o eu, o outro e os objetos. Segundo uma distinção do próprio, as suas inovações fazem-se no modo de organizar o todo narrativo e não na estrutura da língua romanesca; parecendo-Ihe mais fecunda a primeira alternativa, e a outra, um beco sem saída.
\end{abstract}

O Retábulo de Santa Joana Carolina faz parte de uma coleção de narrativas encontradas no livro Nove, Novena de 1966, que traz essas impressões de enredo que o escritor tanto difunde em suas obras. 0 rompimento com a estrutura convencional dos textos narrativos promove outra concepção do ato de ler. Lins permite que o leitor faça correlações de um capítulo a outro para que possa, por exemplo, identificar quem são os narradores em cada mistério.

O desprendimento temporal também é uma identidade presente no conto. Os fatos acontecem sem uma ordem cronológica evidente, contudo, no decorrer da leitura, o receptor consegue estabelecer a ordem dos acontecimentos sem haver uma retomada de capítulos. De acordo com Nitrini (1987, p. 72-73), as narrativas presentes em Nove, Novena são

[...] em geral, fragmentadas em módulos descontínuos, quase sempre coincidentes com parágrafos, apresenta uma cadeia sintagmática truncada, cujas sequências se inserem no sistema da justaposição. Daí a forma do Retábulo como um dos fatores que explicam a descronolização das estruturas, no nível da grande sintagmática narrativa, isto é, das sequências que se encadeiam no texto como um todo.

Recheado de enigmas e simbologias, o conto se fundamenta numa relação de entendimento e descoberta, o leitor estabelece a assimilação, conforme seus componentes inferenciais e, a partir desse pressuposto, é 
convidado a fazer analogias que se desprendem do texto e encaminham o enredo a comparações intertextuais.

Conforme mencionado, o leitor, ao transcender o texto por meio de inferências, conduz sua leitura no cenário que ele reconhece. Aqui está, portanto, a magia da construção textual inserida no Retábulo que instiga o leitor a despertar seu conhecimento prévio e, diante disso, apreciar a habilidade do escritor em dar uma nova roupagem a alguns valores presentes em concepções religiosas ou profanas. Sobre esse aspecto, elucidaremos mais diante.

Como outrora, não podemos definir uma maneira única de analisarmos um texto como este; a ótica de comparar textos, fazer releituras e adequar contextos poderão se tornar uma saída. Cereja (2005) aponta algumas possibilidades de recursos que permitem relacionar textos mais antigos a outros produzidos em gerações mais recentes e com isso, aproximá-los de uma linguagem mais clara e de fácil assimilação. Segundo o autor, a análise de um texto literário não deve apenas ser direcionada para o cumprimento único das habilidades de leitura. Para que de fato o estudo seja mais expansivo e interativo, é salutar contextualizar a dimensão interativa e comunicativa, englobando os princípios dialógicos, estéticos, sociais e ideológicos.

\section{O PROFANO EM O RETÁBULO DE SANTA JOANA CAROLINA ${ }^{2}$}

Um texto repleto de simbologias como o Retábulo de Santa Joana Carolina conduz o leitor a um posicionamento desafiador. Isso se deve à forma como a narrativa é construída e às correlações que o autor faz com algumas concepções do zodíaco e do discurso religioso. No intuito de tentar analisar o comportamento das personagens, à vista dos valores inferenciais que cada leitor inclui no ato de ler, podemos realizar uma pequena conjuntura interpretativa, obtendo inicialmente algumas particularidades do texto que se referem à personalidade de alguns signos do zodíaco.

O conto se inicia com referência ao signo de Libra (primeiro mistério), representado pela nomeação "balança". A balança, por sua vez, remete-nos ao equilíbrio, à justiça, à imparcialidade. É característica do libriano a preocupação com a imagem tanto voltada ao seu próprio eu quanto àquilo que ele representa para o outro. Diante disso, a parteira destaca sua preocupação com Joana:

\footnotetext{
"O lojista, como de posse da balança que pesa as nossas virtudes e pecados, Ihe escreverá uma carta, lembrando que a hora da morte é ignorada e que portanto devemos saldar depressa nossas dívidas, para não sofrer as danações do inferno" (LINS, 1975,p.88)
}

\footnotetext{
2 Informações sobre as características dos signos retiradas do site: https://www.euroresidentes.com/portugues/signos-do-zodiaco/signos-zodiaco.htm Acesso em 09 fev. 2017
} 
O segundo mistério é regido pelo signo de Escorpião, os indivíduos pertencentes a esse signo têm como característica negativa serem ciumentos. Joana, ao manusear os escorpiões de maneira tão desprendida, gera ciúmes no Presidente da Irmandade que se sente inferiorizado e duvida da capacidade da moça, ao afirmar que: "Se a menina faz isso, com os poderes de Deus eu também faço” (LINS, 1975, p.91).

Os sagitarianos são lembrados no terceiro mistério pela figura dos centauros. Joana, doente, apática e sofrida desafia a si mesma representando uma personagem em uma peça teatral. Uma pessoa encontrada enferma e desvalida como ela não deveria se atrever a fazer tal encenação. Contudo, regida por sagitário, Joana faz jus às características do signo. O otimismo e a segurança exacerbados fazem com que os sagitarianos sejam, por vezes, descuidados e irresponsáveis, não se atentando para o resultado infrutífero de seus atos.

A autoconfiança de Totônia, no quinto mistério, evidencia a personalidade de um bom taurino, o que pode ser percebido no seguinte trecho: "Tenho duas torres na cabeça, sou a esposa, a Igreja, a terrena [...]". (LINS, 1975, p.96-97). O taurino demonstra segurança e traz as coisas de forma prática e objetiva. Totônia demonstra esse estereótipo ao convencer Jerônimo José (pretenso marido de Joana) de que ela tem o total domínio de sua família e que esta é muito bem administrada. Como bem peculiar a Lins, o símbolo de touro é encontrado em outros mistérios, fazendo referências ao signo ou ao símbolo que este representa.

O comportamento desprendido e libertário do geminiano pode ser encontrado no nono mistério. Esse trecho da narrativa focaliza Miguel e Cristina e as características de gêmeos podem ser notadas no segmento "Somos os amantes, os fugitivos, os perseguidos, os encontrados, os salvos" (LINS, 1975, p.118).

Já no décimo mistério, destacamos o signo de Câncer. Os cancerianos são emotivos, dramáticos e prestativos. O sofrimento de Jonas, para Joana, era algo que deveria ser amenizado. Como deixar um pobre rapaz sofrer dessa maneira? O sofrimento do rapaz fazia com que Joana, de algum modo, também sofresse, e ela deveria fazer algo para salvá-lo.

A morte de Joana tem um significado muito eloquente no texto. Ela, que foi uma pessoa boa e que sofreu muito durante sua vida, é exaltada em seu leito fúnebre como aquela que deve ser seguida como exemplo de vida e perfeição. Embora a protagonista não tenha se valorizado em nenhum momento da história, elucidar o último mistério como atrelado ao signo de virgem vincula a principal referência desse signo: a perfeição. Perfeição, essa, que Joana só fora reconhecida em sua morte. No decorrer deste último mistério, o autor faz analogias ao signo de Virgem destacando que o fim de Joana se evidenciara por um comportamento virginiano. Lins menciona o signo destacando no trecho, o nome e o mês em que o zodíaco o celebra: "Mas senti 
orgulho de ser mãe dos mortos e viúva, de não morrer virgem, de ter parido vocês. Estamos em setembro? Sim" (LINS, 1975, p. 137).

Aqui, apenas apresentamos algumas incidências que vinculam as ações vivenciadas no conto que se referem às referências comportamentais de alguns signos. Em uma narrativa complexa, como esta, vale uma varredura de leitura mais detalhada, contudo, o que pretendíamos demonstrar, denota a habilidade do autor em escolher pontualmente elementos que, comparados aos signos, revelam atos realizados pelas personagens.

Importa ressaltar que não há marcas convencionais de temporalidade ao longo do conto. Contudo, a passagem temporal é marcada através dos signos. A narrativa inicia-se em outubro, pois, em seu primeiro mistério, há marcas do signo de libra e termina em setembro, período regido pelos virginianos.

\section{MARCAS DE RELIGIOSIDADE}

O nome do livro Nove, Novena já nos remete a um pensamento de cunho religioso. Antes mesmo que tenhamos acesso à leitura dos contos, o título desperta o interesse em desvendar o que essas "novenas" têm a nos dizer.

Em se tratando de um livro, que aparentemente nos revela uma intencionalidade religiosa em seu contexto, espera-se que o autor tenha incluído, em suas histórias, um pouco da sua vivência no ambiente cristão. Contudo, conforme Andrade (1987, p. 26):

\footnotetext{
"Questionado a respeito de sua formação católica, Osman Lins, como bom brasileiro, responde que, apesar de sua fascinação pela lgreja. se vê "impedido talvez pelo lado sensual" de sua "natureza, de ser um verdadeiro católico"”.
}

Por esse caminho seguiremos, expondo algumas particularidades do conto Nove, Novena que demostram marcas que são releituras de passagens bíblicas, tendo como foco a vida da personagem Joana Carolina. Esta, nascida de uma família pobre pelas mãos de uma parteira, já denunciava uma vida de sofrimento e limitações. Comparando com a vida de Cristo, Joana também ascende de uma vida simples, e isso evidencia uma história de muitas lutas e de "santidade".

No segundo mistério, Joana, menina, desafia a todos com a audácia de brincar com escorpiões sem medo de ser picada. Todos admiram sua ousadia e não compreendem o porquê os lacraus não a ferem. Assim, como afirma o Presidente da Irmandade: "Se a menina faz isso, com os poderes de Deus eu também faço”. (LINS, 1975, 91) 
No Antigo Testamento (Gênesis 3.15$)^{3}$, temos uma referência bíblica que se vincula à ação de Joana em não ter medo dos escorpiões (os animais, aqui, considerados no Livro Sagrado como "pequenos demônios"). No trecho: "Porei hostilidade entre ti e a mulher, entre tua linhagem e a linhagem dela. Ela te esmagará a cabeça e tu Ihe ferirás o calcanhar", o diálogo entre Deus e a serpente, após o pecado cometido por Eva, acentua a soberania divina sobre o mal. No conto, Dona Totônia (mãe de Joana) simboliza a passagem bíblica ao esmagar três escorpiões com o pé e finalizar o mistério, ilustrando como o poder de sedução do demônio é mais evidente que a santidade, visto que, o Presidente da Irmandade fica mais incomodado com o fato de Joana não ser picada pelos escorpiões do que aceitar que ela os domina.

O terceiro mistério traz Joana em uma cena representativa muito próxima à passagem de (Isaías 52.14) "Assim como muitas pessoas ficaram pasmadas à vista dele, tão desfigurado estava o seu aspecto como homem, nem parecia um ser humano" ${ }^{4}$. Com Joana, o narrador mensura: "Posso ver que os olhos de Joana são azuis e grandes; e que seu rosto, embora desfigurado, pois ela ainda está convalescente, difere de todos que encontrei, firme e delicado a um tempo" (LINS, 1975, p. 92).

Na passagem bíblica, o profeta prevê o momento da crucificação de Cristo, revela como ficará o teu rosto todo desfigurado pelo sofrimento do qual fora acometido no caminho do Calvário até a sua crucificação. Joana, enferma, também é retratada em uma imagem de martírio e sofrimento, assim como Jesus, inicialmente, ao mencionar que as setas grossas de São Sebastião cravam-se firmes em Joana (p.92), o narrador refere-se a três momentos presentes no discurso bíblico: o primeiro aparece na profecia de Simeão quando Maria e José vão apresentar Jesus no Templo. Nesse local, o profeta diz a Maria que uma espada transpassará em seu coração, o que de fato acontece com o tamanho sofrimento da Virgem no Calvário. O segundo momento refere-se aos cravos que transpassaram os pés e as mãos de Cristo na Cruz. O último remete-nos à flecha que caracteriza o martírio de São Sebastião.

Podemos destacar ainda a semelhança física entre Joana e Jesus. Um exemplo disso aparece no seguinte trecho: "Posso ver que os olhos de Joana são azuis e grandes" (p. 92). Nota-se que a cor dos olhos da personagem remete-nos à imagem de Jesus, a qual, desde o Renascimento, foi retratada com traços europeus.

No quinto mistério, temos o seguinte trecho: "Não é assim que diz a liturgia? Pois se sou fraca, tenho de ser de pedra. Sou de pedra; mas também chorei". A fala é dita por Totônia a Jerônimo, quando este vai pedir a mão de Joana em casamento. Na carta de São Paulo a (II Coríntios 12.10), o profeta diz: "Por isso sinto prazer nas fraquezas, nas injúrias, nas necessidades, nas

\footnotetext{
${ }^{3}$ Informações retiradas do site: http://www.abiblia.org/ver.php?id=7460 Acesso em 13 de fev. 2017.

${ }^{4}$ Retirado do site: http://bibliaportugues.com/isaiah/52-14.htm> Acesso em 13 de fev. 2017.
} 
perseguições, nas angústias por amor de Cristo. Porque quando estou fraco então sou forte". 5 Totônia demonstra o quão se sente forte mesmo tendo repletas dificuldades em ter criado seus filhos. Em outra passagem do texto, a narradora salienta: "[...] sou a esposa, a Igreja, a terrena, a que se polui, a que pare os filhos, a que transforma em leite o próprio sangue, a frágil” (p.96-97). "Transformar o próprio leite em sangue" figura para os cristãos a imagem do pelicano que simboliza Cristo. A ave é tão atenciosa com os teus filhotes, que em momentos de ausência de comida, é capaz de dar a carne do próprio coração para alimentá-los. ${ }^{6}$

No quinto mistério, também encontramos uma cena enigmática da vida de Cristo representada pela singeleza da personagem Joana. Diante da morte de seu marido, na sutileza de seu simplório coração, Joana repete os atos de Cristo na última ceia ao se sentar no centro da mesa e repartir o pão com os seus cinco filhos, sendo dois sentados à sua direita e o restante à esquerda. Esse momento se identifica consoante à passagem em que Jesus reparte o pão entre os discípulos, assim como relata o evangelista Lucas: "Enquanto comiam, Jesus tomou o pão, deu graças, partiu-o e o deu aos seus discípulos, dizendo: Tomem e comam; isto é o meu corpo" (Lucas 22.14-16). ${ }^{7}$

O narrador do sexto mistério também afirma essa habilidade de Joana "em repartir o pão" devido à sua garra em não permitir ser persuadida por ele. "Multiplica os pães, os peixes? Absurda mulher. Nunca entendi suas contas, ela possuía o dom da multiplicação". (p. 103). A multiplicação dos pães é considerada uma das manifestações mais enigmáticas dos milagres de Cristo. Jesus, segundo os evangelistas, vendo que a multidão que o seguia tinha fome, pediu que trouxessem cinco pães e dois peixes, e eis que o milagre aconteceu:

Disse Jesus: "Mandem o povo assentar-se". Havia muita grama naquele lugar, e todos se assentaram. Eram cerca de cinco mil homens. Então Jesus tomou os pães, deu graças e os repartiu entre os que estavam assentados, tanto quanto queriam; e fez o mesmo com os peixes. ${ }^{8}$ (João $6.10-11$ )

No sétimo mistério, Joana amaldiçoa o tempo em que viveu no Engenho Serra Grande, pois foram sete anos de muita luta e sofrimento. Andava muito para vender seus crochês na cidade e seus filhos foram acometidos por uma doença. Isso pode ser comprovado no seguinte trecho: "Sete anos, sete meses e sete dias morei neste inferno. Sete anos, sete meses e sete dias. Parece uma sentença escrita num livro". (p. 111)

\footnotetext{
${ }^{5}$ Retirado do site: < https://www.bibliaonline.com.br/acf/2co/12>. Acesso em 13 de fev. 2017

${ }^{6}$ Fonte: < http://cleofas.com.br/divino-pelicano-eb/> Acesso em 13 de fev. 2017.

${ }^{7}$ Fonte: < https://www.bibliaon.com/ultima_ceia/> Acesso em 13 de fev. 2017.

${ }^{8}$ Fonte: < https://www.biblegateway.com/passage/?search=Jo\%C3\%A3o+6\&version=NVI-PT> Acesso em 13 de fev. 2017.
} 
Talvez o "livro" a que Joana se refere está no antigo testamento, quando José ao interpretar um sonho do faraó, avisa que, durante sete anos, seu povo sofrerá muitas mazelas, um tempo de fome e sede:

\begin{abstract}
"O faraó teve um único sonho", disse-lhe José. "Deus revelou ao faraó o que ele está para fazer. As sete vacas boas são sete anos, e as sete espigas boas são também sete anos; trata-se de um único sonho. As sete vacas magras e feias que surgiram depois das outras, e as sete espigas mirradas, queimadas pelo vento leste, são sete anos. Serão sete anos de fome. (Gênesis 41,25-27) ${ }^{9}$
\end{abstract}

Não poderia faltar o "milagre de Joana". Ela, preocupada com o estado deplorável de Jonas, resolve cortar os pés do leito onde o rapaz vivia, diminuindo seu acesso ao chão. Sem saber, Joana havia salvado a vida de Jonas. O rapaz fora salvo de uma bala, pois se não tivesse em uma posição mais baixa, teria tido um trágico fim. Joana, por sua vez, não o curou, mas sem saber garantiu a ele uma nova oportunidade de viver.

Por fim, destacamos, no último mistério, a referência que Lins faz ao dilúvio. Joana, mulher guerreira e sofrida, torna-se um "ser celestial" por sua vida simples e de boa conduta. Como mérito por seus atos, a pobre mulher é vista como uma redentora, aquela que, após uma grande tormenta, poderá gerar bons frutos, conforme segue:

[...] nunca tivemos a impressão tão viva e tão perturbadora de que esta é a arca do Próximo Dilúvio, que as novas águas vingativas tombarão sobre nós quarenta dias e quarenta noites, afogando até as cobras e as traíras, e que somente Joana sobreviverá, para depois gerar como um gesto os seres que lhe aprouver: plantas, bichos, Javãs, Magogs, Togarmas, Asquenazes (p. 135)

\title{
CONCLUSÃO
}

Seria imprudente afirmar que conseguimos, neste trabalho, demonstrar todas as referências que Osman Lins fez em suas linhas muito bem elaboradas. Um autor cuja maestria se expõe em cada mistério, levando-nos a refletir diversas situações que vivenciamos ou temos uma diretriz de quem poderia vivenciá-las.

A astrologia é algo que desperta o imaginário, é comum termos o interesse de observar como o comportamento do nosso signo interfere nas escolhas que temos, salvo àqueles que não acreditam nessa ideologia, muitos se valem dessas concepções para conduzirem projetos de vida.

Lins traz em sua obra um grande desafio, atrevemo-nos a dizer: uma grande mistura de valores. Ao mesmo tempo, ele conduz a uma ideologia

\footnotetext{
${ }^{9}$ Fonte: https://www.biblegateway.com/passage/?search=G\%C3\%AAnesis+41\&version=NVIPT Acesso em 15 de fev. 2017.
} 
considerada profana juntamente com referências voltadas ao ambiente do sagrado. Isso ocorre, na narrativa, ao considerar temas bíblicos e profanos voltados às atitudes de sua heroína, Joana Carolina.

Vinculados ao conceito de inferência e dos referenciais dialógicos bakhtinianos, promovemos uma análise, buscando interpretar, de certo modo, como podemos vivenciar a leitura do conto no princípio do conhecimento prévio do leitor. Perante isso, é salutar afirmamos que um conto como o Retábulo de Santa Joana Carolina não se limita apenas ao que foi escrito neste artigo, na verdade, pretendemos despertar para novas leituras ou até mesmo para o aprofundamento do que iniciamos.

\title{
THE SACRED AND THE PROFANE IN THE RETÁBULO DE SANTA JOANA CAROLINA OF OSMAN LINS
}

\begin{abstract}
His article aims to analyze the short story Retábulo de Santa Joana Carolina. It focus on the study of the inferential marks present in the narrative that enable the religious and profane conceptions included in its plot. The aim of this paper is to investigate the religious symbologies inserted in the text and the typical behavior of the zodiac signs. This paper is based on the reading inferential concepts and in the dialogical conceptions of Bakhtin. The analysis was made after some fragments of the text were selected to demonstrate indications linked to the religious and astrological environment and were compared to biblical verses and to the behavioral analysis of the star signs. As a result, it was noticed that Osman Lins, during the narrative, suggests evidences that when compared to biblical parts and star signs studies are references for an interpretative reading that transcends the context, awakening the reader's previous knowledge. Therefore, it can be concluded that when the readers relate their knowledge they became able to make new reading perspectives, through dialogical and inferential relations enabled by the text.
\end{abstract}

Keywords: Dialogism; Inference; Concepts of Reading; Osman Lins.

\section{REFERÊNCIAS}

ANDRADE, Ana Luiza. Osman Lins: crítica e criação. São Paulo: Hucitec, 1987.

BAKHTIN, Mikhail M. Os gêneros do discurso. In. Estética da criação verbal. Trad. Paulo Bezerra. São Paulo: Martins Fontes, 2011. p.261-306. 
BOSI, Alfredo. História Concisa da Literatura Brasileira. São Paulo: Cultrix, 2012.

BRAIT, B. Bakhtin e a natureza constitutivamente dialógica da linguagem. In: Brait, B. Bakhtin, dialogismo e construção de sentido. 2.ed. São Paulo:Editora Unicamp, 2005.

CÂNDIDO, Antônio. A personagem de ficção. São Paulo: Perspectiva, 1987.

CEREJA, W. R. Ensino de Literatura: uma proposta dialógica para o trabalho com a literatura. São Paulo: Atual, 2005.

COSCARELLI, C. V. Reflexões sobre as inferências. Anais do VI CBLA Congresso Brasileiro de Linguística Aplicada, Faculdade de Letras da UFMG, CD Rom, 2002.

UFMG. Maio, 2003. Disponível em:

<http://bbs.metalink.com.br/ Icoscarelli/piblica.htm>

FIORIN, J.L. Introdução aos pensamentos de Bakhtin. 2. ed. São Paulo: Contexto, 2016.

GAMA, Rinaldo. Metáfora estrutural de Osman Lins alça novo voo. In: Entre livros. São Paulo, Ediouro - Dueto, n¹, 2006.

LINS, Osman. "Retábulo de Santa Joana Carolina". In: BOSI, Alfredo - Org. O conto Brasileiro Contemporâneo. São Paulo: Cultrix, 1975.

NITRINI, Sandra. Poéticas em confronto Nove, Novena e o novo romance. São Paulo: Editora Hucitec, 1987.

VARGAS, Diego da S. Por uma visão cognitivista do processo de inferenciação em leitura. Ciências \& Cognição, V.20, n. 2, p. 313-330, 2015. Disponível em: $<$ HTTPS://cienciase cognicao.org> 